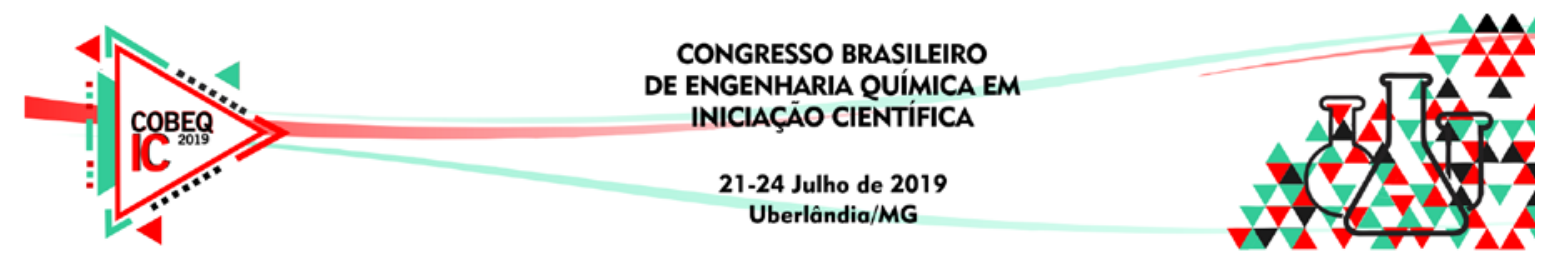

\title{
AVALIAÇÃO DE CORRELAÇÕES EMPÍRICAS PARA ESTIMATIVA DE PONTO DE CONGELAMENTO DE HIDROCARBONETOS PUROS E FRAÇÕES DE PETRÓLEO
}

\author{
O. A. A. LONGE, S.M. SANTOS e L.V.FREGOLENTE \\ Universidade Estadual de Campinas, Faculdade de Engenharia Química \\ E-mail para contato: oaalonge@gmail.com
}

\begin{abstract}
RESUMO - O ponto de congelamento, propriedade de grande importância para querosene de aviação, é preferencialmente obtido por métodos experimentais. Porém, para minimizar custos na caracterização e obtenção do ponto de congelamento de hidrocarbonetos puros e de frações de petróleo, realizou-se uma pesquisa bibliográfica em busca de correlações que estimassem essa propriedade e posteriormente, avaliou-se a acuracidade das correlações através de dados experimentais da literatura. Como resultado, observou-se que apenas as correlações para hidrocarbonetos puros apresentaram resultados aderentes aos dados experimentais utilizados. Assim, novas correlações foram propostas para estimativa de ponto de congelamento para frações de petróleo com ponto de congelamento entre $140 \mathrm{~K}$ e $290 \mathrm{~K}$, querosene e diesel, com melhores AAD de 9,0 K, 3,1 K e 4,5 $\mathrm{K}$, respectivamente.
\end{abstract}

\section{INTRODUÇÃO}

O ponto de congelamento de uma substância representa a temperatura em que toda a fase líquida de uma amostra torna-se sólida (RIAZI, 2005), sendo importante para diversas aplicações, como na determinação do grau de pureza de compostos (SHIMIZU et al., 2008), identificação de compostos desconhecidos (SMITTENBERG; HOOG; HENKES, 1938), conservação e estabilização de produtos farmacêuticos (TANG; PIKAL, 2004) e adequação a especificações de combustíveis utilizados em baixas temperaturas (ASTM, 2018), como querosene de aviação.

Para hidrocarbonetos puros, o ponto de congelamento é a temperatura onde o líquido se solidifica a $1 \mathrm{~atm}$, neste caso assumindo o mesmo valor que o ponto de fusão (RIAZI, 2005). Para misturas, como frações resultantes da destilação do petróleo, define-se o ponto de congelamento como sendo a temperatura em que desaparece o último dos cristais formados pelo resfriamento prévio da fração de petróleo, quando se reaquece essa fração sob constante agitação (FARAH, 2012). A composição da mistura em termos de componentes parafínicos, naftênicos e aromáticos é determinante para o valor do ponto de congelamento (AFFENS et al., 1984), sendo que em linhas gerais compostos parafínicos possuem maior ponto de congelamento.

Assim, o presente trabalho tem como objetivo analisar a validade de correlações presentes na literatura para a previsão do ponto de congelamento de hidrocarbonetos puros e frações de petróleo, além de desenvolver novas correlações para estimativa dessa propriedade para as frações. 


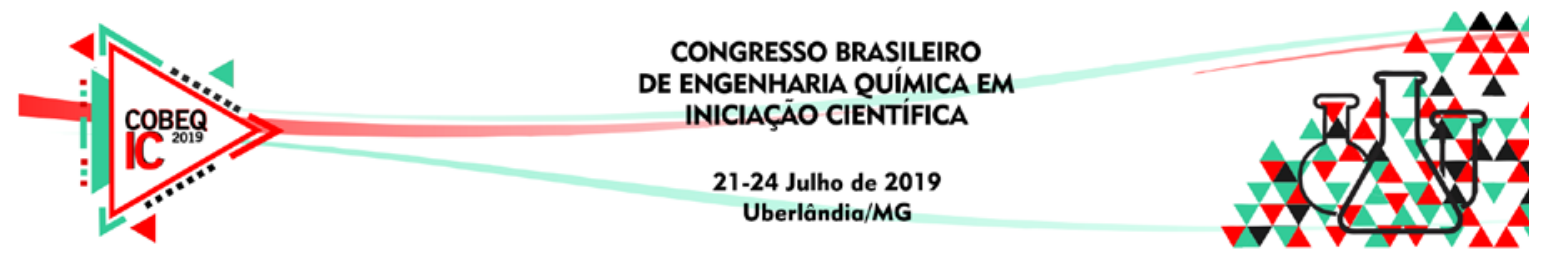

\section{METODOLOGIA}

\subsection{Avaliação de métodos existentes para hidrocarbonetos puros}

Após revisão bibliográfica, foram levantadas as Equações de 1 a 5 mostradas na Tabela 1, para estimativa do ponto de congelamento de diferentes classes de hidrocarbonetos puros. Conforme Tabela 1, os métodos já desenvolvidos para estimativa do ponto de congelamento possuem como variável independente apenas a massa molar (M) do composto, na unidade g/mol e são restritos a uma classe individual de hidrocarbonetos.

Para verificação da qualidade de predição de tais modelos, foram utilizados 73 dados experimentais de hidrocarbonetos apresentados obtidos na literatura (RIAZI, 2005) e em banco de dados de substancias puras PubChem.

Tabela 1 - correlações para ponto de congelamento de hidrocarbonetos puros

\begin{tabular}{cccc}
\hline RESTRIÇÃO & MODELO & REFERENCIA & \#EQ \\
\hline Para n-parafinas & $P C=374,5+0,02617 \cdot M-20172 / M$ & (WON, 1986) & (1) \\
Para alcanos: C5-C40 & $P C=397-\exp \left(6,5096-0,14187 \cdot M^{0,47}\right)$ & $\begin{array}{c}\text { (RIAZI e A1- } \\
\text { SAHHAF, 1995) } \\
\text { (RIAZI e A1- }\end{array}$ & (2) \\
Para alquilciclopentanos:C7-C41 & $P C=370-\exp \left(6,52504-0,04945 \cdot M^{2 / 3}\right)$ & $\begin{array}{c}\text { SAHHAF, 1995) } \\
\text { (RIAZI e A1- }\end{array}$ & (3) \\
Para alquilciclohexanos:C7-C20 & $P C=360-\exp \left(6,55942-0,04681 \cdot M^{0,7}\right)$ & $\begin{array}{c}\text { SAHHAF, 1995) } \\
\text { (RIAZI e A1- }\end{array}$ & (4) \\
Para alquilbenzeno: C9-C42 & $P C=375-\exp \left(6,53599-0,04912 \cdot M^{2 / 3}\right)$ & SAHHAF, 1995) & (5) \\
\hline
\end{tabular}

\subsection{Avaliação de métodos existentes para frações de petróleo}

Através da revisão bibliográfica, encontrou-se até o momento apenas um modelo para estimativa de ponto de congelamento para fração de petróleo, Equação 6 (DAUBERT; DANNER, 1997). Neste caso, o ponto de congelamento é relacionado com a densidade da fração a $15,6^{\circ} \mathrm{C}\left(\mathrm{d}_{15,6}\right)$, fator de caracterização API $\left(\mathrm{K}_{\mathrm{api}}\right)$ e ponto de ebulição médio mediano em graus celsius (PEMe).

$$
P C=-1638,03+1014,14 \cdot d 15,6+68,05 \cdot K_{A P I}-0,135 \cdot P E M e
$$

Para avaliação da qualidade de predição desta correlação, foram utilizados 43 dados experimentais de assays de petróleo da empresa ExxonMobil.

\subsection{Ajuste de novas equações para frações de petróleo}

Após a avaliação da Equação 6, duas novas abordagens para ponto de congelamento de frações de petróleo foram aplicadas com o objetivo de obter maior acuracidade na estimativa do ponto de congelamento de frações de petróleo. 


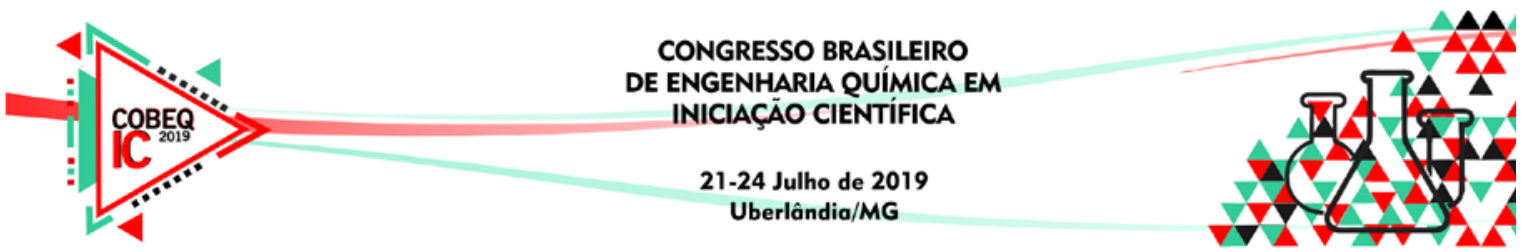

Na primeira abordagem, a partir do método API (Equação 6), ajustou-se novos coeficientes através dos dados experimentais de assays da empresa ExxonMobil. Neste caso, os dados foram separados e ajustados em uma nova correlação para cortes de nafta, querosene e diesel. As novas correlações foram obtidas através do software Labfit, um programa computacional que realiza regressão linear e não linear através do método dos mínimos quadrados (SILVA et al., 2004). Nos ajustes obtidos, foram avaliados os coeficientes de determinação $\left(\mathrm{R}^{2}\right)$ e Absolute Average Deviation (AAD) para verificação da qualidade das equações em relação às previsões dos dados experimentais. O AAD é obtido através da razão entre a somatória das diferenças entre valores experimentais e os calculados pelo número de pontos experimentais utilizados. (ALMEHAIDEB, 2003).

Para a segunda abordagem, determinou-se novas correlações, através do LabFit, ajustando equações aos dados experimentais das assays da ExxonMobil para cada corte de óleo cru, como nafta, querosene e diesel. Além dos ajustes para as faixas de nafta a diesel, foi ajustada uma equação empírica de predição de ponto de congelamento para frações com pontos de congelamento de $140 \mathrm{~K}$ até $290 \mathrm{~K}$, não limitada a determinado corte básico de destilação como nos casos anteriores. Neste caso, foram utilizados dados de 120 assays de três companhias de petróleo (BP, Equinor e ExxonMobil).

No desenvolvimento das novas correlações, foram considerados três parâmetros que são de fácil obtenção em refinarias ou campos de produção de petróleo e que potencialmente influenciam o valor do ponto de congelamento, tais como o ponto de ebulição médio mediano, densidade a $15,6{ }^{\circ} \mathrm{C}$ e a viscosidade cinemática a $40^{\circ} \mathrm{C}$. Estes parâmetros estão relacionados ao tamanho da cadeia da molécula e tipo de hidrocarboneto: parafínico, naftênico ou aromático.

\section{RESULTADOS E DISCUSSÃO}

\subsection{Métodos existentes para hidrocarbonetos puros}

Os resultados apresentados pelas correlações para hidrocarbonetos puros, Equações 1-5 (Figura 1) foram considerados satisfatórios, uma vez que há grande proximidade dos valores preditos em relação aos valores encontrados na bibliografia. Para alquilciclopentanos e alquilciclohexanos, Equações 3 e 4, apesar dos resultados serem considerados satisfatórios, para maior certificação quanto a acuracidade, seriam necessários avaliar o método com maior número de dados experimentais.

\subsection{Estimativa de ponto de congelamento para frações de petróleo}

Ao testar o modelo API, Equação 6, foram observados elevados desvios em relação aos valores experimentais. Assim, para aumentar a acuracidade da estimativa do ponto de congelamento, prosseguiu-se com as abordagens 1 e 2 .

Na abordagem 1, os novos parâmetros ajustados a partir do formato da Equação 6 são mostrados na Tabela 2, sendo as Equações 7 e 8 obtidas para os cortes de querosene e diesel, respectivamente. Verifica-se que os valores preditos aproximaram-se dos valores experimentais. O corte de nafta não apresentou resultado satisfatório devido à equação obtida apresentar resultados distantes dos valores experimentais. 


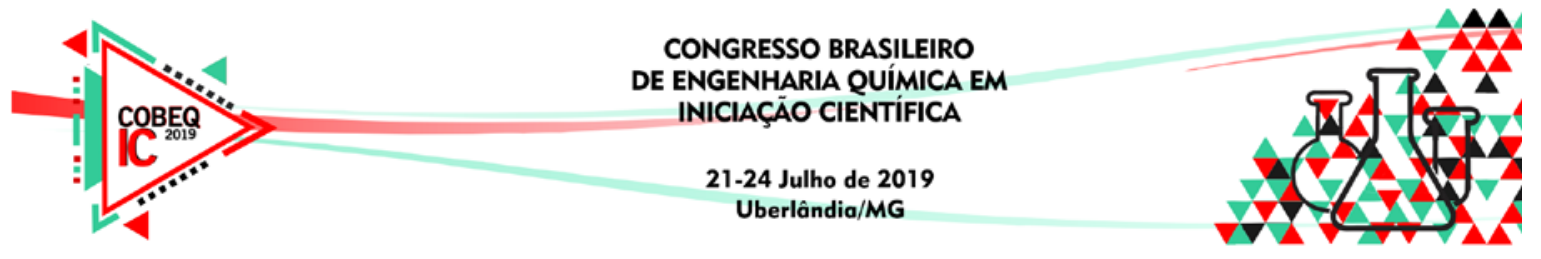

Tabela 2 - Correlações Ajustadas utilizando o modelo da equação 6

\begin{tabular}{lcccc}
\hline \multicolumn{1}{c}{ NOVAS CORRELAÇÕES } & RESTRIÇÃO & R $^{2}$ & AAD & \#EQ. \\
\hline $\mathrm{PC}=22234,15-15029,68 \cdot \mathrm{d}_{15,6}-1007,20 \cdot$ & Corte de & 0,70 & $5,0 \mathrm{~K}$ & $(7)$ \\
$\mathrm{K}_{\mathrm{API}}-8,41 \cdot \mathrm{PEMe}$ & querosene & & & \\
\hline $\mathrm{PC}=26766,52-17075,92 \cdot \mathrm{d}_{15,6}-1219,15 \cdot$ & Corte de diesel & 0,79 & $6,3 \mathrm{~K}$ & $(8)$ \\
$\mathrm{K}_{\mathrm{API}}+7,43 \cdot \mathrm{PEMe}$ & & & & \\
\hline
\end{tabular}

$\mathrm{Na}$ segunda abordagem, ajustaram-se novas correlações aos dados experimentais, obtendo-se diferentes resultados, dependendo do corte da fração de petróleo. As Equações 9 e 10 foram ajustadas para frações de petróleo com valores de ponto de congelamento acima de $180 \mathrm{~K}$ e abaixo de $280 \mathrm{~K}$, obtidas através de 129 dados experimentais provindas de 43 assays, que resultaram em um AAD de aproximadamente $8 \mathrm{~K}$. As equações de 11 a 14 foram ajustadas a partir das mesmas 43 assays e a Equação 15 ajustada a partir de 300 dados experimentais de refinarias variadas (BP, Equinor e ExxonMobil).

Como resultado positivo, é importante destacar os resultados satisfatórios para o diesel 4,5 K, e principalmente para o querosene 3,1 K (Tabela 3, Equação 11-14). Já para o corte de nafta os resultados não foram adequados apresentando $\mathrm{AAD}=11,0 \mathrm{~K}$ e R $\mathrm{R}^{2}=0,25$.

Além disso, através do desenvolvimento da Equação 15, é possível realizar a estimativa para frações com ponto de congelamento entre $140 \mathrm{~K}$ e $290 \mathrm{~K}$, abrangendo cortes da faixa de nafta a diesel, tendo menor desvio em relação aos dados experimentais (AAD = 9,0 K), se comparado com o método API para frações de petróleo em geral, Equação 6, que para os dados analisados apresentou AAD = 11,3 K. Dessa maneira, a Equação 15 se mostra como uma melhor alternativa em relação à Equação 6 por apresentar um AAD menor e depender de menos parâmetros e que podem ser obtidos experimentalmente com maior facilidade.

Tabela 3 - Correlações Ajustadas para Frações de Óleo Cru

\begin{tabular}{|c|c|c|c|c|c|}
\hline NOVAS CORRELAÇÕES & RESTRIÇÃO & $\mathbf{R}^{2}$ & Parâmetros & AAD & \#EQ. \\
\hline $\begin{array}{l}P C=0,9 \cdot P E M e-671.5 \cdot d_{15,6}-5,4 \cdot \\
v+326,0\end{array}$ & $\begin{array}{l}\text { Para a faixa de } \\
\text { nafta a diesel } \\
\quad \text { (Exxon) }\end{array}$ & 0,85 & $\begin{array}{c}\text { PEMe }\left({ }^{\circ} \mathrm{C}\right) \\
v_{40}{ }^{\circ} \mathrm{C}(\mathrm{CSt}), d_{15,6}\end{array}$ & $8,2 \mathrm{~K}$ & $(9)$ \\
\hline $\begin{array}{l}P C=-2188,3 \cdot\left(d_{15,6}\right)^{3}+3039,2 \cdot \\
\left(d_{15,6}\right)^{2}-1275,9 \cdot d_{15,6}+0,8 \cdot P E M e\end{array}$ & $\begin{array}{l}\text { Para a faixa de } \\
\text { nafta a diesel } \\
\text { (Exxon) }\end{array}$ & 0,86 & PEMe $\left({ }^{\circ} \mathrm{C}\right), d_{15,6}$ & $8,3 \mathrm{~K}$ & (10) \\
\hline$P C=\frac{P E M e}{-312,6+363,3 \cdot d_{15,6}}-33.3$ & $\begin{array}{l}\text { Para querosene } \\
\text { (Exxon) }\end{array}$ & 0,90 & PEMe $\left({ }^{\circ} \mathrm{C}\right), d_{15,6}$ & $3,1 \mathrm{~K}$ & (11) \\
\hline$P C=\frac{(-5,1+v)}{\left(6,8-8,0 \cdot d_{15,6}\right)}-42,7 \cdot d_{15,6}$ & $\begin{array}{l}\text { Para querosene } \\
\quad \text { (Exxon) }\end{array}$ & 0,91 & $d_{15,6}, v_{40{ }^{\circ} \mathrm{C}}(\mathrm{cSt})$ & $3,1 \mathrm{~K}$ & (12) \\
\hline$P C=\frac{(1,4-0,005 \cdot \mathrm{PEMe})}{\left(1-2,2 \cdot d_{15,6}+1,5 \cdot\left(d_{15,6}\right)^{2}\right)}$ & $\begin{array}{l}\text { Para diesel } \\
\text { (Exxon) }\end{array}$ & 0,90 & PEMe $\left({ }^{\circ} \mathrm{C}\right), d_{15,6}$ & $4,5 \mathrm{~K}$ & (13) \\
\hline$P C=\frac{(59,9-0,2 \cdot \mathrm{PEMe})}{\left(1-0,3 \cdot v+0,02 \cdot v^{2}\right)}$ & $\begin{array}{l}\text { Para diesel } \\
\text { (Exxon) }\end{array}$ & 0,89 & $\begin{array}{c}\text { PEMe }\left({ }^{\circ} \mathrm{C}\right) \\
v_{40}{ }^{\circ} \mathrm{C}(\mathrm{CSt})\end{array}$ & $4,9 \mathrm{~K}$ & (14) \\
\hline $\begin{array}{l}P C=-3715.8 \cdot\left(d_{15,6}\right)^{39.7}-131.4 \cdot \\
e^{-0.69 \cdot v}\end{array}$ & $\begin{array}{l}\text { Para a faixa de } \\
\text { nafta a diesel (BP, } \\
\text { Equinor, Exxon) }\end{array}$ & 0,77 & $d_{15,6}, v_{40{ }^{\circ} \mathrm{C}}(\mathrm{cSt})$ & $9,0 \mathrm{~K}$ & (15) \\
\hline
\end{tabular}




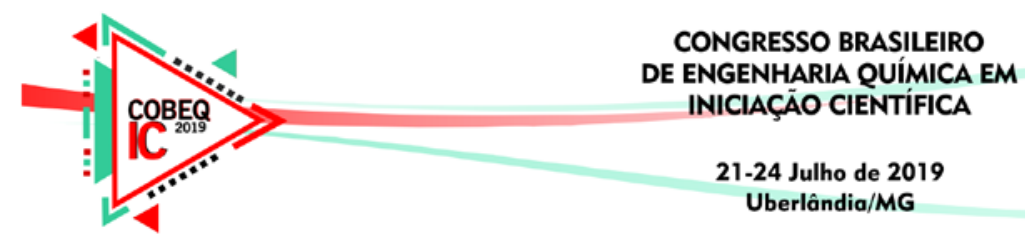

Figura 2- Ajuste para o corte na faixa de querosene

Figura 1 - Métodos de estimativa de PC para hidrocarbonetos puros

Métodos de estimativa de PC para

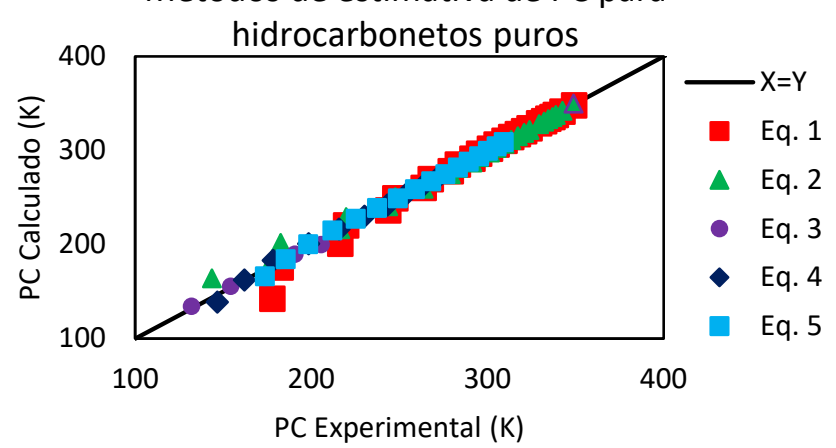

Figura 3 - Ajuste para o corte na faixa de diesel utilizando o modelo da Eq. 6

Ponto de Congelamento - Diesel

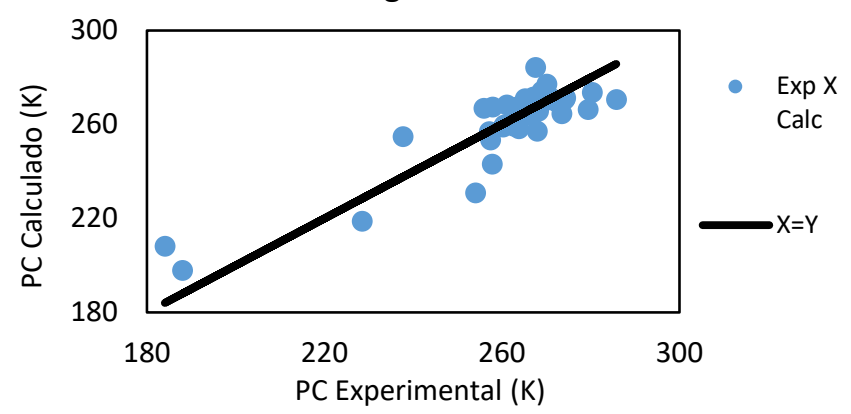

Figura 5 - Ajustes para o corte na faixa de querosene

Ponto de Congelamento - Querosene

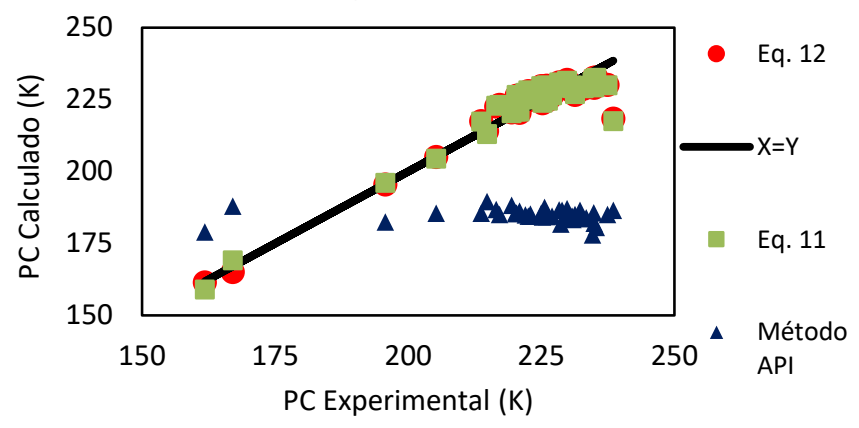

utilizando o modelo da Eq. 6

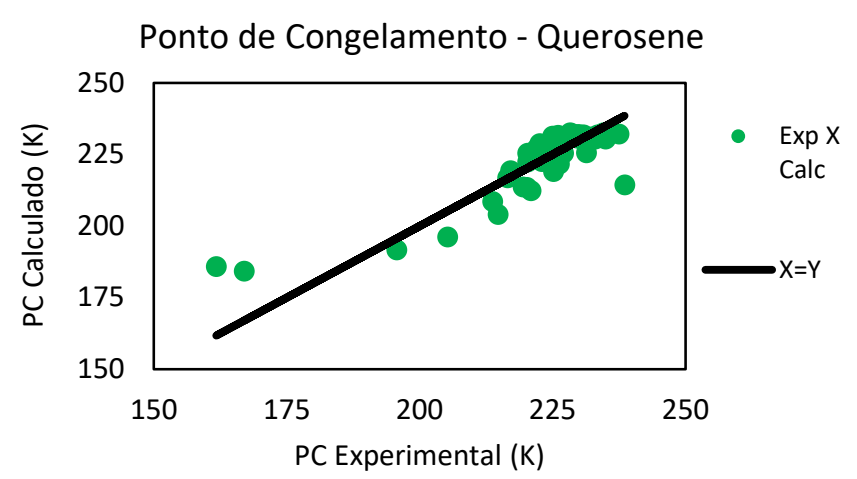

Figura 4 - Ajustes para os cortes com PC entre 180 $\mathrm{K}$ e $280 \mathrm{~K}$

Ponto de Congelamento - Nafta a Diesel

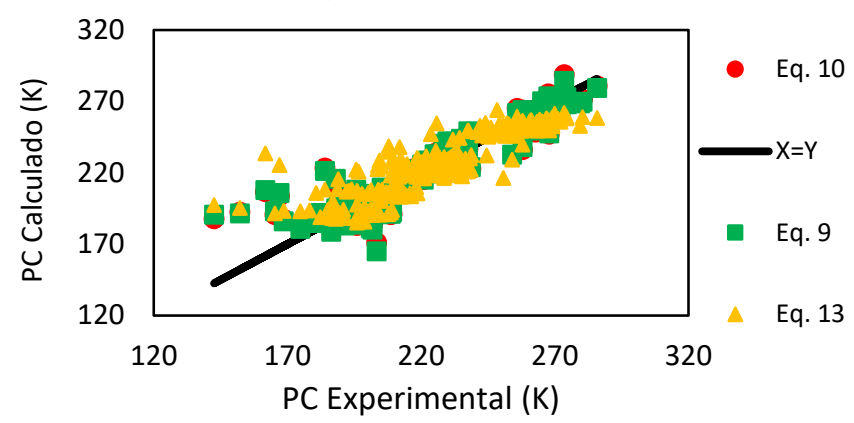

Figura 6 - Ajustes para o corte na faixa de diesel

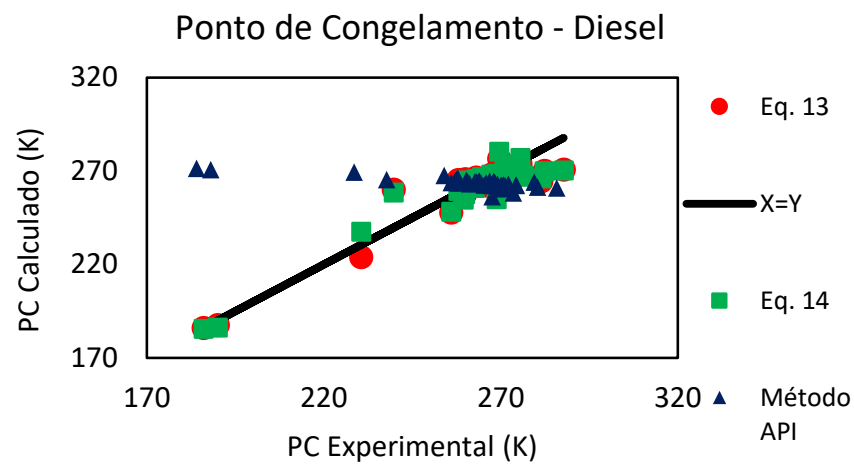

\section{CONCLUSÕES}

Foi possível concluir, a partir dos resultados obtidos, que os métodos existentes para a estimativa do ponto de congelamento para substâncias puras tiveram resultados satisfatórios para os dados testados não sendo necessário o desenvolvimento de novas correlações. Já para a aplicação do único método até o momento encontrado na literatura para frações de petróleo, o método API, os resultados não foram considerados adequados. Assim, através da abordagem 2, obteve-se ajustes adequados para os cortes de querosene e diesel, com $\mathrm{R}^{2}$ superiores a 0,89 e AAD menores que 4,9 K e para frações com ponto de congelamento entre $140 \mathrm{~K}$ e $290 \mathrm{~K}$, com $\mathrm{R}^{2}=0,85$ e $\mathrm{AAD}=8,3 \mathrm{~K}$. 


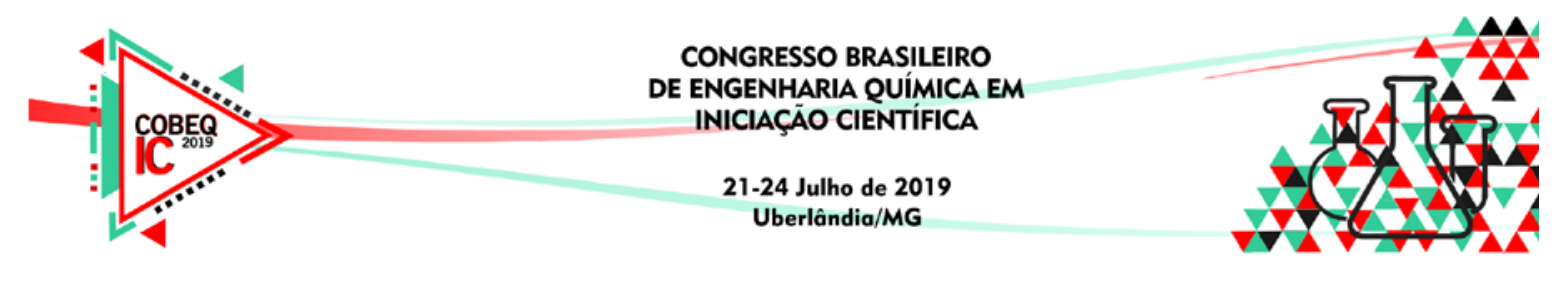

\section{AGRADECIMENTO}

Os autores agradecem à Petrobras pelo suporte financeiro, através do processo $\mathrm{n}^{\circ}$ 5850.0108456.18.9.

\section{REFERÊNCIAS}

AFFENS, W. A. et al. Effect of composition on freezing points of model hydrocarbon fuels. Fuel, v. 63, n. 4, p. 543-547, abr. 1984.

ALMEHAIDEB, R. A. (2003). Improved Correlations for Fluid Properties of UAE Crude Oils. Petroleum Science and Technology, 21, pp. 1811-1831.

ASTM D2386-18, Standard Test Method for Freezing Point of Aviation Fuels, ASTM International, West Conshohocken, PA, 2018

DAUBERT, T. E.; DANNER, R. P. API Technical Data Book - Petroleum Refining. American Petroleum Institure, Washington DC, n. 6, 1997.

EXXONMOBIL. Disponível em: <https://corporate.exxonmobil.com/en/company/worldwideoperations/crude-oils/assays>. Acesso em: 29 jan. 2019.

FARAH, M. A. Petróleo e seus derivados: definição, constituição, aplicação, especificações, características de qualidade. Rio de Janeiro: LTC, 2012.

THE PUBCHEM PROJECT. Disponível em: <https://pubchem.ncbi.nlm.nih.gov/>. Acesso em: 22 mar. 2019.

RIAZI, M. (ED.). Characterization and Properties of Petroleum Fractions, First Edition. 100 Barr Harbor Drive, PO Box C700, West Conshohocken, PA 19428-2959: ASTM International, 2005.

SILVA, W. P. DA et al. “LAB Fit ajuste de curvas”": um software em português para tratamento de dados experimentais. Revista Brasileira de Ensino de Física, v. 26, n. 4, p. 419427, dez. 2004.

SHIMIZU, Y. et al. Development of certified reference materials of high-purity volatile organic compounds: purity assay by the freezing-point depression method. Accreditation and Quality Assurance, v. 13, n. 7, p. 389-396, jul. 2008.

SMITTENBERG, J.; HOOG, H.; HENKES, R. A. Freezing Points of a Number of Pure Hydrocarbons of the Gasoline Boiling Range and of Some of their Binary Mixtures. Journal of the American Chemical Society, v. 60, n. 1, p. 17-22, jan. 1938.

TANG, X. (CHARLIE); PIKAL, M. J. Design of Freeze-Drying Processes for Pharmaceuticals: Practical Advice. Pharmaceutical Research, v. 21, n. 2, p. 191-200, fev. 2004. 